\title{
Selective Growth of Si Nanowire Arrays via Galvanic Displacement Processes
}

By Di Gao, Rongrui He, Carlo Carraro, Roger T. Howe, Peidong Yang, and Roya Maboudian

\author{
Supporting Information
}

Experimental procedure

Two substrates, $\mathrm{Si}(111)$ (p-type, Boron doped) for vertically aligned Si nanowires, and patterned (110) silicon-on-insulator (SOI) for horizontally aligned Si nanowires are employed in the study. The SOI wafers consist of $80 \mu \mathrm{m}$ thick Si(110) layer, $2 \mu \mathrm{m}$ thick silicon oxide layer, and $400 \mu \mathrm{m}$ thick $\mathrm{Si}(100)$ substrate. About $1 \mu \mathrm{m}$ thick thermal oxide film is first grown in $\mathrm{H}_{2} \mathrm{O}$ vapor at $1050{ }^{\circ} \mathrm{C}$, which serves as an etch mask for the Si deep reactive ion etching (DRIE). The oxide film is then patterned by plasma etch after a photolithography step. All the features are designed to expose sidewalls consisting of (111) surfaces. The Si(110) layer is then etched through to make Si pillars using a Bosch DRIE process in an inductively-coupled plasma etcher (Surface Technology Systems). The sidewalls in (111) planes are further chemically polished by dipping in hot $\mathrm{KOH}$ solution $\left(33 \%\right.$ in $\left.\mathrm{H}_{2} \mathrm{O}, 80^{\circ} \mathrm{C}\right)$ for 5 seconds. The final structure is schematically presented in Fig. S1.

The reversed micelle microemulsions are prepared by mixing a water-based plating solution with $n$-heptane and a surfactant, sodium bis(2-ethylhexyl) sulfosuccinate (AOT, $\mathrm{C}_{20} \mathrm{H}_{37} \mathrm{O}_{7} \mathrm{SNa}$ ). ${ }^{13}$ The water-based solution consists of $0.2 \mathrm{M} \mathrm{HF}$ and $0.01 \mathrm{M} \mathrm{KAuCl} 4$. The AOT/heptane solution is made by dissolving $0.33 \mathrm{M}$ AOT in $\mathrm{n}$-heptane. The two solutions are mixed in appropriate ratios to make microemulsions with different $\mathrm{R}$ values. Here, $\mathrm{R}$ is the ratio of the molar concentration of $\mathrm{H}_{2} \mathrm{O}$ to that of AOT in the final microemulsions $\left(\mathrm{R}=\left[\mathrm{H}_{2} \mathrm{O}\right] /[\mathrm{AOT}]\right)$. As a comparison, the galvanic experiment is also performed in the water-based solution without mixing with AOT/heptane. The Si(111) substrates and the (110) SOI substrates with Si pillars are immersed in the microemultions with different R for 30 seconds to deposit Au clusters. The Au clusters are examined by scanning electron microscopy (SEM, LEO 1550) afterwards.

The procedure and apparatus for the $\mathrm{Si}$ nanowire growth have been described elsewhere. ${ }^{8,9}$ Silicon tetrachloride $\left(\mathrm{SiCl}_{4}\right.$, $\mathrm{Aldrich}$ $99.99 \%$ ) is used as the silicon source. The deposition temperature is $950{ }^{\circ} \mathrm{C}$. The CVD process parameters are kept the same for all the nanowire growth experiment. The samples are examined by scanning electron microscopy afterwards.

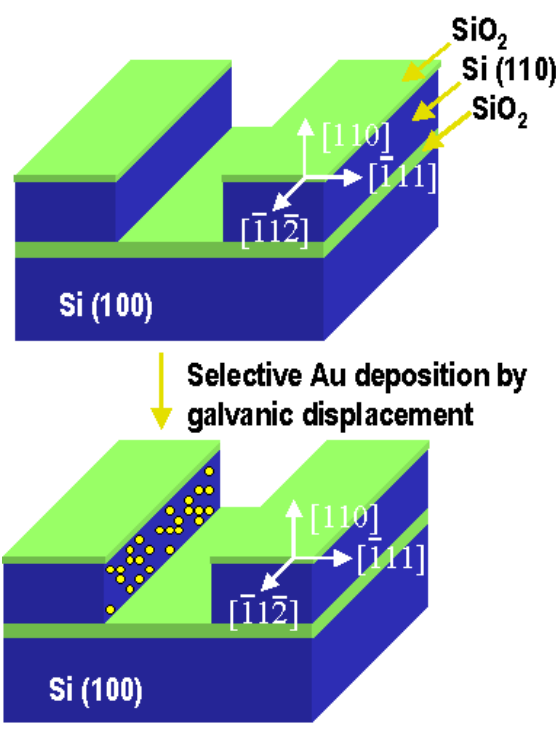

Figure S1. Schematic illustration of structures fabricated on (110) SOI wafers for the growth of laterally aligned Si nanowire arrays. 

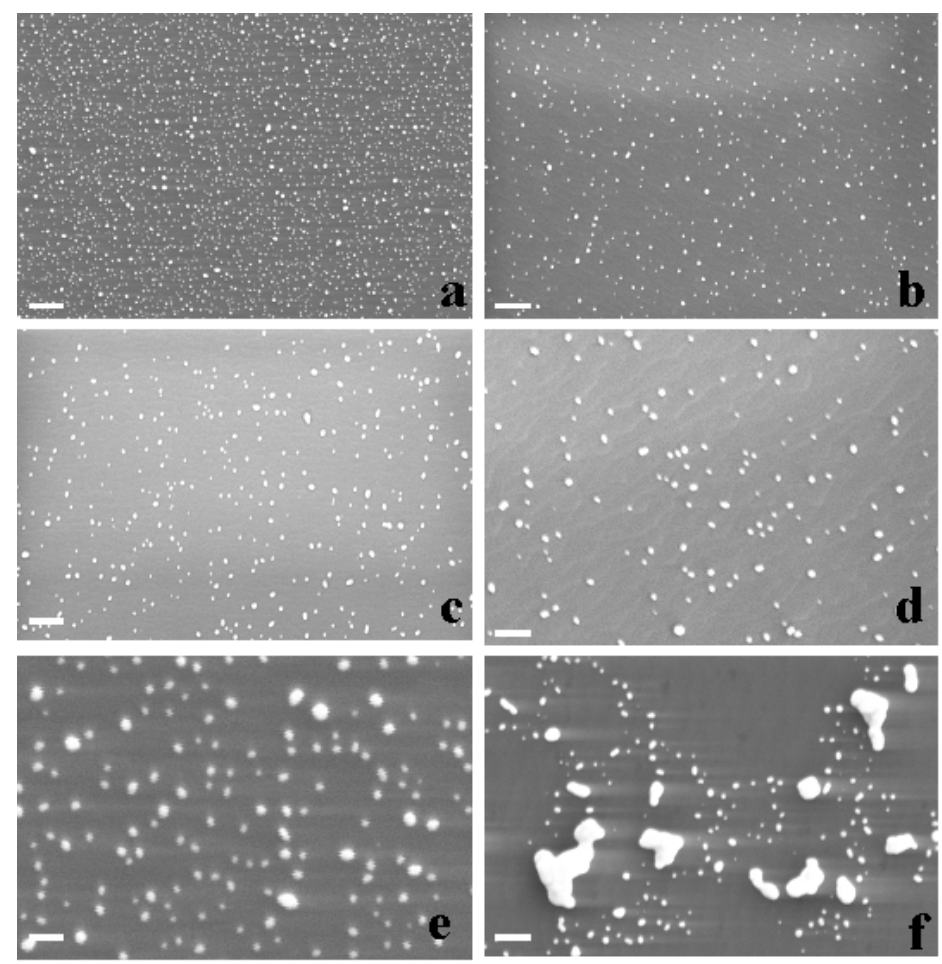

Figure S2. SEM images of Au clusters deposited on $\mathrm{Si}(111)$ substrates by the galvanic displacement process using microemulsions with $\mathrm{R}$ values of 16 (a), 25 (b), 50 (c), 100 (d), and 200 (e), respectively, and water-based solution (f). The scale bar is $300 \mathrm{~nm}$. 